\title{
Addressing health challenges in the five regional priority areas: progress in one year
}

\author{
Ala Alwan ${ }^{7}$
}

When I took office as Regional Director early in 2012, I laid out a strategic vision for action in the Region in five key areas (1), a vision that was endorsed by the WHO Regional Committee for the Eastern Mediterranean at its Fiftyninth session (EM/RC59/R.1). I am now midway through my term and this month, when the Regional Committee meets in Tunis for its sixty-first session, Ministers of Health and senior officials in Member States will discuss the current health situation in the Region and progress in regard to the five strategic health priorities.

Our region is passing through a turbulent period in its history. The number of countries and areas experiencing conflict and instability is unprecedented in modern times, and the numbers of people displaced within and beyond their own borders are on a scale unseen ever before. This has added another challenge to implementing the already ambitious agenda set by the Regional Committee. Nevertheless, the past two and half years have seen important strategic decisions and developments.

At the heart of the five priority areas is the health system itself. Agreement was reached early on in regard to the issues Member States needed to focus on in order to strengthen their health systems and move towards universal health coverage: leadership and governance, financing, work force, access to essential technologies, health care delivery and quality of services, and health information systems (EM/RC59/R.3) (2). Last year, at its Sixtieth session, the Committee agreed on a strategy and road map for achieving universal health coverage (EM/RC60/R.2) (3). There are gaps in all countries in the different health system components. Our work in WHO has been to recommend effective solutions and build capacity to address these gaps. Countries need to move forward on developing national road maps to achieve universal health coverage, expand social health insurance coverage and ensure quality in health services.

Maternal and child health was also identified as a priority (EM/RC60/R.6) (4). In the past two years, several Member States embarked upon implementing acceleration plans with a view to moving more rapidly towards achieving the United Nations targets - Millennium Development Goals 4 and 5 - for reducing maternal and child mortality. Implementation is well under way and, although the targets are unlikely to be met by end 2015 in some high-burden countries, the lives of many more women and children will have been saved and the way paved for continuing improvement beyond 2015. Unfortunately, in other countries that were doing well on this front, we are now seeing setbacks as mothers and children are forced from their homes and villages by conflict. The progress achieved since 2000 is in danger.

The burden of noncommunicable diseases (NCDs) is rising rapidly as populations age and as lifestyles change. All Member States in the Region are facing challenges in responding to this burden. In 2012, the Regional Committee endorsed a regional framework for action (EM/RC59/R.2) (5). While there are some promising initiatives in some countries in regard to implementing some parts of the framework, there are also some serious gaps in the response to this growing epidemic, with only a few countries so far having developed national multisectoral action plans. Action taken by countries to implement proven preventive measures needs to be strengthened. Some countries have started implementing population-level salt reduction, but there is still a long way to go to tackle the high levels of overweight and obesity, the high intake of salt, fat, sugar and calories, and the very high levels of tobacco use. All countries need to take concrete action to address the pernicious marketing of unhealthy foods and sweetened beverages to our children and adolescents. The risk to health posed by lack of physical activity should be taken much more seriously. Our work in addressing NCDs over the past two years has focused on translating the sound vision and clear road map provided by WHO into the regional framework for action, and on providing Member States with technical guidance to scale up evidence-based interventions to reduce risk factors and promote health care, particularly at the primary health care level. With increasing emphasis given to NCDs at the World Health Assembly and the United Nations General Assembly, countries are now accountable to scale up action against the epidemic.

Health security is uppermost in all our minds at this time as Ebola virus disease takes its terrible toll in West Africa, Middle East Respiratory Syndrome 
(MERS-CoV) continues to infect people in our region, and polio and measles threaten resurgence in conflict-affected countries and their neighbours. One of the major tools to ensure health security for everyone is implementation of the International Health Regulations as adopted by all Member States at the Fifty-eighth session of the World Health Assembly in 2005 (WHA58.3). The Regulations impose obligations to develop and maintain core public health capacities to detect, assess, notify and report events of international concern. So far only eight States Parties to the Regulations have indicated their readiness to meet the obligations. The final deadline for readiness is June 2016. Therefore much work needs to be done within the next two years. The countries in the Region that are not yet ready have all submitted new plans to meet the deadline that is all the more pressing with every outbreak and every new emerging disease. I look forward to early and intensive implementation of these plans.

With the final strategic priority, we come full circle. In a region where emergency response is stretching resources to the utmost, so preparedness becomes ever more important. The lessons of the past have not been, and are not being, learnt in this Region. The most important of these is to include public health preparedness, including readiness to implement the International Health Regulations, within a comprehensive national emergency plan. This is the all-hazard approach recommended by the United Nations and its partners (6), an approach that has served countries around the world well, including low-income countries.

As the Regional Committee discusses the progress to date, it is very clear that hard work lies ahead.

\section{References}

1. Shaping the future of health in the WHO Eastern Mediterranean Region: reinforcing the role of WHO. Cairo: WHO Regional Office for the Eastern Mediterranean; 2012.

2. Health systems strengthening in countries of the Eastern Mediterranean Region: challenges, priorities and options for future action. Cairo: WHO Regional Office for the Eastern Mediterranean; 2012 (http://applications.emro.who. int/docs/RC_technical_papers_2012_Tech_Disc_1_14613_ EN.pdf?ua=1, accessed 7 October 2014).

3. Towards universal health coverage: challenges, opportunities and roadmap. Cairo: WHO Regional Office for the Eastern Mediterranean; 2013 (http://applications.emro. who.int/docs/RC_Techn_paper_2013_tech_disc_2_15016_ EN.pdf?ua=1, accessed 7 October 2014).

4. Saving the lives of mothers and children. Cairo: WHO Regional Office for the Eastern Mediterranean; 2013
(http://applications.emro.who.int/docs/RC_Techn_paper_2013_3_15019_EN.pdf?ua=1, accessed 7 October 2014).

5. The Political Declaration of the United Nations General Assembly on the Prevention and Control of Non-Communicable Diseases: Commitments of Member States and the way forward. Cairo: WHO Regional Office for the Eastern Mediterranean; 2012 (http://applications.emro.who.int/ docs/RC_technical_papers_2012_3_14578_EN.pdf?ua=1, accessed 7 October 2014).

6. Hyogo framework for action 2005-2015: Building the resilience of nations and communities to disasters. Geneva: United Nations, International Strategy for Disaster Reduction; 2007 (Extract from the final report of the World Conference on Disaster Reduction (A/CONF.206/6) (http://www.who. int/hac/events/2013/online_consultation_hyogo_framework_for_action.pdf?ua=1, accessed 8 October 2014). 